\title{
O percurso do vocábulo profeta na dicionarística de língua portuguesa
}

\author{
Thiago Wallace Rodrigues dos Santos Lopes ${ }^{\mathrm{i}}$
}

\section{RESUMO}

O presente trabalho buscou descrever o percurso da palavra profeta na tradição dicionarística da Língua Portuguesa. Para esse fim, buscamos tratar questões relacionadas à ciência lexicográfica, ou Lexicografia, e à Lexicologia, para entendermos como as ciências do léxico se desenvolveram em Portugal e no Brasil. Em seguida, apresentamos um relato acerca da história dos dicionários e apresentamos os percursos deles na história de Portugal e na do Brasil; nesse ponto, buscamos apresentar algumas das diferenças, que podem ser observadas, entre a lexicografia dos dois países. Para finalizar, escolhemos olhar o vocábulo profeta a partir da visão de quatro importantes obras à ciência lexicográfica do português e são elas: o Vocabulário do padre Rafael Bluteau (1728), o Dicionário de Caldas Aulete (1881), o Dicionário Etimológico de Antenor Nascentes (1955) e o Grande Dicionário Houaiss da Língua Portuguesa do filólogo Antônio Houaiss e do lexicógrafo Mauro de Salles Villar (2009). Após a escolha dos dicionários, fizemos a análise da entrada para o verbete em cada um desses dicionários e, por fim, apresentamos as nossas considerações finais.

Palavras-chave: Lexicologia; Lexicografia; Dicionarística; Dicionário; Profeta.

\begin{abstract}
This paper aims at studying the history of the word prophet in the Portuguese dictionary tradition. To that end, I have sought to address issues related to lexicographic science, or lexicography, and lexicology, in order to understand how the lexicon sciences developed in Portugal and Brazil. Therefore, here I present an account of the history of dictionaries and their paths in the history of Portugal and Brazil. At this point, I look forward to inspect some of the diferences that can be observed between the lexicography of the two countries. Finally, I chose to look at the word prophet from the perspective of four important works of lexicographic science in Portuguese. Those are the vocabulary of Father Rafael Bluteau (1728), the Dictionary of Caldas Aulete (1881), the Etymological Dictionary of Antenor Nascentes (1955), and the Great Houaiss Dictionary of the Portuguese Language by the philologist Antônio Houaiss and the lexicographer Mauro de Salles Villar (2009). After choosing the dictionaries, I analyzed each entry in those dictionaries and ultinately presented my final considerations.
\end{abstract}

Keywords: Lexicology; Lexicography; Dictionary; Prophet.

\footnotetext{
${ }^{\text {i }}$ Mestre em Letras - Língua Portuguesa pelo Programa de Pós-graduação em Letras da Universidade do Estado do Rio de Janeiro (UERJ, 2020). Integra, desde junho de 2019, o grupo de Pesquisa Estudos Linguísticos, Multiletramentos e Ensino de Língua Portuguesa (ELMEP/CNPq). É professor voluntário do curso Ascensão Pré-vestibular Social. thiagodossantos16@gmail.com | https://orcid.org/0000-0001-7921-4631
} 


\section{PARA INICIAR A CONVERSA}

O presente artigo se propõe a descrever o percurso dicionarístico do verbete profeta na tradição lexicográfica de Língua Portuguesa. Para isso, tomamos como arcabouço teórico as teorias da Lexicografia e da Lexicologia, com maior uso da tradição lexicográfica; valemo-nos, também, dos dicionários produzidos em Língua Portuguesa (doravante, será também referida como LP).

Começamos, portanto, o trabalho tratando da tradição lexicográfica e da sua importância para os estudos linguísticos; para este fim, abordou-se sua origem e seu desenvolvimento como ciência. Focamos na Lexicografia do português, abordando os seus atrasos e avanços. Além disso, fizemos uma breve distinção entre Lexicografia e Lexicologia, com vistas a estabelecer e compreender suas semelhanças e diferenças.

Em seguida, apontamos a história dos dicionários de Língua Portuguesa, falando dos bilíngues e dos monolíngües e tratando da importância de cada um deles para os estudos diacrônicos da língua. Para tanto, trabalhamos aqueles produzidos em Língua Portuguesa, apresentando alguns dos que foram produzidos em Portugal e no Brasil, tendo como foco os que utilizamos para a análise do percurso do vocábulo profeta. Tal escolha se deu a partir do destaque e da importância que cada um dos dicionários trabalhados apresentou em sua época, bem como das suas contribuições para a Lexicografia de LP e para a valorização do vernáculo português.

A partir desse ponto, apresentamos quatro visões diferentes acerca do verbete discutido, isto é, mostramos a definição de quatro dicionários diferentes, publicados em épocas distintas, para o termo que analisamos. Com isso, pretendemos mostrar as diferentes acepções para o verbete. Por fim, apresentaremos nossas considerações finais para o presente trabalho.

\section{A LEXICOGRAFIA E A LEXICOLOGIA}

Apesar de o saber lexical ser algo presente em toda a história das línguas naturais, fez-se importante o desenvolvimento de técnicas para estudar os vocábulos. Surgem, com isso, duas ciências: a Lexicologia e a Lexicografia. A Lexicologia é a 
ciência que estuda o vocábulo por um viés histórico, buscando entendê-lo por diversos pontos de vista, ou seja, ela, segundo Cunha (1997, p.319),

é o setor da linguística que trata do estudo dos vocábulos, examinando, com a possível minúcia, todos os aspectos pertinentes, tais como a sua evolução histórica, a sua etimologia, a frequência de uso deste ou daquele termo, enfim, todo o vasto estudo relacionado com o Léxico.

Em contrapartida, a Lexicografia surge com o intuito de cuidar " [...] da ciência, das técnicas e das metodologias específicas para a elaboração de dicionários, vocabulários, glossários e índices vocabulares de diversa natureza [...]” (CUNHA, 1997, p. 319), produzindo um perfil histórico e descritivo dos itens lexicais de uma dada língua. Assim, segundo Farias (2007, p.89):

[...] não podemos afirmar que a atividade lexicográfica tenha sido desenvolvida na Antiguidade, pois bem antes desse período a paleolexicografia já havia alcançado desenvolvimento expressivo, uma vez que os eblaítas, sumérios, acadianos e babilônios já haviam produzido suas listas bilíngues.

Vemos, portanto, que os primeiros textos com teor lexicográfico surgem ainda na antiguidade; desse período, contudo, temos apenas "referências a obras lexicográficas gregas, que influenciaram na elaboração de repertórios egípcios monolíngues, aos glossários produzidos em Alexandria e ao Appendix Probi, do século III d.C." (FARIAS, 2007, p. 89-90). Essas obras, que englobavam os glossários produzidos pela escola de Alexandria, preocupavam-se com a leitura e a compreensão de textos literários (BIDERMAN, 1984).

A Lexicografia, porém, estrutura-se “[...] como disciplina linguística desde a primeira metade do século XVI, em vários centros humanísticos europeus [...]" (VERDELHO, 2002, p. 15), em grande parte, motivada pelo resgate do ensino não materno do Latim como língua literária, de cultura e de comunicação internacional. Para além disso, a ciência lexicográfica surge com um intuito descritivo da língua, encarregando-se de desenvolver materiais que buscavam definir e descrever as palavras, com fins pedagógicos. Assim, surgiram dicionários bilíngues, que abordavam o Latim e o vernáculo com vistas a facilitar o resgate da educação em língua latina. Após esse período, os dicionários passaram a ser monolíngues, descrevendo apenas o vernáculo, dando maior valorização às línguas nacionais (CUNHA, 1997; VERDELHO, 2002; VERDELHO, 2007; FARIAS, 2007; SILVESTRE, 2008). 
A Lexicografia de Língua Portuguesa, segundo Cunha (1997), mostra-se devedora, atrasada e ainda em desenvolvimento quando relacionada à das outras línguas europeias. Foi, porém, “muito bem estudada no século XVIII e no primeiro quartel do século XIX” (CUNHA, 1997, p. 323), mas, podemos observar que há ainda muito a ser feito no tocante às pesquisas lexicográficas em Língua Portuguesa, com o intuito de compreender e descrever melhor seus itens lexicais.

Temos, por fim, duas ciências que estudam o léxico, a Lexicologia e a Lexicografia. Ambas apresentam maneiras diferentes de abordar os estudos lexicais, porém, são complementares entre si, pois o "[...] saber lexicográfico resulta de um longo processo de instrumentação, cuja origem não está em um acontecimento isolado, mas em uma série de fatos inter-relacionados [...]" (NUNES, 2002, p. 102). Propomo-nos, portanto, a tratar da questão lexicográfica da Língua Portuguesa em relação ao verbete profeta. Assim, ao apresentar o percurso desta Ciência Linguística e o tratamento dado ao verbete em destaque, acreditamos poder perceber melhor os efeitos e os ambientes comunicativos em que ele tem sido utilizado, principalmente por vermos o discurso religioso cada vez mais presente em nossa sociedade. Dessa maneira, a palavra foi tratada a partir da visão de quatro dicionários produzidos em LP, sendo dois portugueses e dois brasileiros. Por esse fator, apresentamos um pouco da história da produção dessas obras em português.

\section{OS DICIONÁRIOS DE LÍNGUA PORTUGUESA}

Os dicionários em Língua Portuguesa tiveram suas origens, segundo Verdelho (2007), nos glossários medievais que surgiram no século XIII. Esses eram elaborados de forma bilíngue, em latim e na língua vernácula, e utilizados, pelas línguas vulgares da Europa, como auxílio à escolarização em latim. Nesse período gera-se “[...] uma espécie de lexicografia implícita que tecia os próprios textos e facilitava a compreensão do vocabulário característico da escrita, forçosamente mais amplo e menos quotidiano do que o da língua oral [...]” (VERDELHO, 2002, p. 15). Nunes afirma que

\footnotetext{
o dicionário, segundo Auroux, é um "instrumento lingüístico", e como tal ele "prolonga a fala natural", dando acesso a formas que não figuram na "competência" de um locutor. Trata-se de um "instrumento tecnológico" que não corresponde a algo que estaria inscrito na mente do sujeito, mas a algo que lhe é exterior. (2002, p. 101)
} 
A Lexicografia tem, portanto, a função de reunir os itens lexicais que compõem o léxico de uma língua e defini-los, de modo a tornar mais fácil a compreensão de textos escritos. Essa reunião se faz importante, pois, de acordo com Biderman,

\begin{abstract}
o léxico de uma língua natural registra o conhecimento do universo na forma de palavras. Ora, o tesouro vocabular de um idioma constitui um conjunto de dimensões indeterminadas. De fato, o número total de palavras de uma língua de civilização pode atingir uns 500.000 vocábulos ou mais. Além disso, sendo um conjunto aberto, novas palavras são criadas continuamente pelos usuários, especialmente os mais cultos e mais criativos, e também pelos cientistas (as terminologias científicas), embora qualquer falante possa contribuir para a geração lexical. (2003, p. 53)
\end{abstract}

Tal ciência busca registrar os vocábulos da língua, e outros elementos lexicais usados na formação de palavras, em listas de glossários e vocabulários, em geral bilíngues latim-português, que depois foram reunidos em dicionários de língua. Estes começaram seguindo a tradição bilíngue, pois visavam à escolarização em língua latina. Com o aumento da valorização do vernáculo, os dicionários passaram à fase monolíngue, a qual empregava maior valor à língua nacional e buscava a melhor compreensão desta (BIDERMAN, 1984; VERDELHO, 2002; VERDELHO, 2007; FARIAS, 2007).

Assim, como “[...] a questão da valorização do património linguístico e literário português passa pela edição de dicionários [...]” (SILVESTRE, 2008, p. 7), são produzidos, no final do século XVI e na primeira metade do XVII, os primeiros dicionários em LP. Essas obras lexicográficas tiveram como fonte os textos de Nebrija (1492), Calepino (1502) e de Estienne (1531) (BIDERMAN, 1984; VERDELHO, 2002; VERDELHO, 2007). Dessa forma, iniciou-se o processo de dicionarização do português. Apresentamos aqui alguns dos dicionários produzidos em LP.

\title{
DICIONÁRIOS EM PORTUGAL
}

O processo de dicionarização da Língua Portuguesa, em Portugal, foi marcado pela produção de dicionários humanistas, como os que foram produzidos por Jerónimo Cardoso, com o intuito de resgatar e apresentar influências da antiguidade clássica (VERDELHO, 2002; BIDERMAN, 2003; VERDELHO, 2007), dentre os quais, mais se destaca "o Dictionarium ex Lusitanico in Latinum Sermonem (1562)" (VERDELHO, 2002, p. 17, grifos do autor). Desta maneira, 


\begin{abstract}
o pequeno dicionário de Cardoso deve ser assim considerado como o padrão inicial da lexicografia do português. Não obstante a modéstia das suas dimensões, oferece um "corpus" lexical interessante e muito significativo para a época, composto por cerca de 12.100 formas diferentes, distribuídas por um pouco mais de 12.000 entradas a que foram ainda acrescentadas 728 na segunda edição (1569). (VERDELHO, 2007, p. 14).
\end{abstract}

Além de ser o ponto inicial da dicionarização do português, a obra de Cardoso foi, também, a pioneira em promover uma 'alfabetação do 'corpus' lexical vernáculo e deu assim origem, com maior ou menor interferência, a todos os subsequentes dicionários do português" (VERDELHO, 2002, p. 18). Tornou-se, por isso, o precursor dos demais dicionários produzidos em Portugal e também uma importante fonte de referência para os estudos filológicos que trabalham com a diacronia, além de se tornar uma marca "[...] no levantamento das unidades lexicais, na referenciação do seu valor semântico, e na fixação da sua imagem ortográfica” (VERDELHO, 2007, p 14).

É, também, importante destacar que, apesar de ser um dicionário bilíngue, a obra de Cardoso trouxe uma importante significação para o vernáculo do português; com isso, inicia-se o processo de prestigiar a língua nacional, acrescentando "[...] uma abundante informação lexicográfica no respeitante à língua vernácula” (VERDELHO, 2002, p. 18).

Após Jerónimo Cardoso, houve outras produções lexicográficas que deram origem a dicionários, que também são de grande importância para a história lexicográfica da LP, mas que não se destacaram na mesma proporção que o dicionário de Cardoso. Dentre esses, podemos citar o de Agostinho Barbosa, que possui um corpus latino autorizado, exemplos de textualização das entradas e acumula, na parte portuguesa, uma quantidade significativa de sinônimos; e o manual escolar intitulado Raizes da lingua latina mostradas em hum tratado, e diccionario: isto he, hum compendio do Calepino com a composição, e derivação das palavras, com a ortografia, quantidade e frase dellas, de Amaro Reboredo. Trata-se de um dicionário trilíngue, latim-português-espanhol, que era usado para o ensino do latim, principalmente, como língua de cultura, porém muitas entradas não possuem correspondência em LP (BIDERMAN, 1984; VERDELHO, 2002; BIDERMAN, 2003; VERDELHO, 2007).

A partir de então surgem, também visando à escolarização em latim, os dicionários produzidos pelos Jesuítas, que, “desde a sua instalação em Portugal, nos meados do séc. XVI, empenharam-se na produção de manuais escolares, especialmente 
voltados para a formação linguística, e criaram assim uma estudiosa escola de gramáticos e dicionaristas" (VERDELHO, 2007, p. 16), muitos desses se destacaram por produzirem obras lexicográficas da língua de missão brasileira (língua desenvolvida a partir do contato do português com as línguas indígenas, com o intuito de catequizar os índios), da qual tratamos mais à frente. Tratando especificamente das produções Jesuítas em terras portuguesas,

\begin{abstract}
temos notícia de trabalhos de Fernando Pires, António Velez, Manuel de Gouveia, Manuel Barreto, Bento Pereira, Matias de S. Germano, António Franco e José Caeiro. Alguns dos seus textos mantêm-se manuscritos e aguardam um estudo que os apresente ao público e que aprecie o seu interesse para a história da língua e da cultura portuguesa. É o caso do Vocabulario Lusitanico Latino de Manuel BARRETO (c. 1561-1620), "composto na Provincia de Japão", concluído em 1607, que se guarda manuscrito em 3 volumes na Biblioteca da Academia das Ciências de Lisboa. (VERDELHO, 2002, p.21, grifos do autor)
\end{abstract}

Além dessas obras produzidas pelos jesuítas, há também a obra Prosodia (1634) de Bento Pereira, que é a obra mais representativa da Lexicografia jesuíta que foi produzida em Portugal, além de ser

\begin{abstract}
um volumoso manual escolar composto por um dicionário amplíssimo de latim-português, ao qual se juntou, a partir de 1661, um dicionário de português-latim Tesouro da língua portuguesa (que fora primeiramente publicado autónomo em 1647) e ainda um conjunto de textos paralexicais (Frases portuguesas a que correspondem as mais puras e elegantes latinas; Adágios portugueses com seu latim proverbial correspondente; e uma Tertia pars selectissimarum descriptionum, quas idem auctor vel olim a se compositas, vel a probatissimis scriptoribus emendicatas alphabetico ordine digessit) que serviam para aprendizagem escolar e para exercitação da escrita e da oratória. (VERDELHO, 2007, p. 17 grifos do autor)
\end{abstract}

Faz-se necessário registrar que o Tesouro da língua portuguesa foi uma importante referência para que a nomenclatura lexical da LP fosse fixada. A obra passou, durante o século XVII, por reedições que não apresentaram muitas alterações, mesmo com a revisão da Prosodia em 1697, na qual houve a manutenção das 240.000 entradas do dicionário. Foi esta edição que continuou a ser publicada até 1755. Para além dessas obras, os Jesuítas editaram ainda outros dois dicionários de cunho escolar, são eles o Index totius artis, de António Velez, que foi anexado à Gramática de Manuel Álvares; e o Indiculo Universal, que foi editado em 1716 e apresenta um texto onomasiológico, trabalhando as entradas em ordem alfabética e não levando em conta o campo semântico das entradas; foi traduzido do francês e adaptado para português (VERDELHO, 2002; CAMERON, 2007; VERDELHO, 2007;). 
Após a tradição dicionarística dos jesuítas, o dicionário do clérigo Rafael Bluteau foi o texto lexicográfico de maior expressão. A obra de Bluteau tomou grande espaço no campo de estudos da Lexicografia de Língua Portuguesa, tornando-se uma obra monumental da Lexicografia portuguesa. Assim, o

\begin{abstract}
Vocabulario Portuguez, e Latino de Rafael Bluteau (1638-1734), publicado entre 1712 e 1728, é o ponto de referência fundamental para compreender um processo de renovação da descrição da língua, da tipologia dos dicionários e das funções que os leitores atribuíam a estes instrumentos metalinguísticos. (SILVESTRE, 2008, p. 7, grifos do autor)
\end{abstract}

A obra do padre torna-se, então, a principal referência para os dicionários que foram publicados depois dele, visto que o conteúdo lexicográfico que o padre usa para construir sua obra é bastante rico e, apesar de ser considerado bilíngue (latimportuguês), “[...] o latim é objecto de uma informação muito sumária e tão pouco significativa, no conjunto da obra, que pode ser considerada essencialmente monolíngue" (VERDELHO, 2002, p. 22).

O corpus lexicográfico do Bluteau, segundo Silvestre (2007), é composto por cerca de 7.200 páginas, às quais se acresciam dicionários de especialidades e glossários que juntos totalizam cerca de 500 páginas. Há, ainda, no dicionário, 200 páginas de conteúdo paratextual. O Vocabulario Portuguez, e Latino compreende 42.000 entradas e uma massa textual de mais de três milhões de palavras na parte que compõe as informações; dessas cerca de três quartos são do vernáculo português.

O Vocabulário foi reeditado e publicado até 1728. Com isso, Bluteau gerou um fundo lexical e documental para os lexicógrafos que vieram após ele; isso está ligado, também, ao fato de a obra do clérigo apresentar um caráter enciclopédico. Segundo Silvestre (2007; 2008), esse fundo foi de fundamental importância para os dicionaristas dos séculos XVIII e XIX, que se apoiaram na obra do padre.

Seguindo a tradição, temos a presença do carioca António de Morais e Silva com o seu Dicionário da língua portuguesa, que foi publicado pela primeira vez em 1789. Segundo Silvestre (2008), é com o dicionário de Morais e Silva que se inicia a Lexicografia moderna da LP. Foi uma obra muito importante para o patrimônio lexicográfico português, porque, além de reduzir os dez volumes do Bluteau a dois, acrescentou cerca de 22.000 entradas, o que corresponde a um acréscimo de um terço a mais que as do Vocabulário de Bluteau, as quais são recolhidas de autores portugueses (BIDERMAN, 1984; VERDELHO, 2007; SILVESTRE, 2008). O Dicionário da língua 
portuguesa toma proporções tão importantes aos estudos lexicográficos que passa por diversas reedições até o século XIX.

O dicionário de Morais e Silva marcou o início da moderna Lexicografia de Língua Portuguesa, por fixar a tradição dos dicionários monolíngues e por ser o primeiro dicionário produzido nesse novo momento dos estudos lexicográficos. Junto a ele temos outros dicionários que são publicados nesse período. Entre eles, Verdelho (2007) cita o Dicionário da Academia Real de Ciências, publicado em 1793, que é o maior e mais significativo intento normativo acerca da Língua Portuguesa; o Elucidário, de 1798/99, preparado pelo Frei Joaquim de Santa Rosa de Viterbo, que, por ser um registro do português arcaico, facilita a leitura de textos documentais; o Dicionário poético, publicado em 1765 por Cândido Lusitano, entre outros.

A partir do século XIX, a Lexicografia monolíngue portuguesa "foi bastante abundante, sem, todavia, atingir um nível de qualidade e quantidade comparável ao de outras línguas europeias" (VERDELHO, 2002, p. 31). Dessa forma, além do Morais, que passou por muitas reedições, sendo algumas delas no Brasil, surgiram outros dicionários que foram importantes para a dicionarística de LP. Dentre eles, citamos o Grande Dicionário Portuguez ou Thesouro da Lingua Portugueza, de Domingos Vieira, publicado entre 1872 e 1874, que foi a obra mais volumosa e mais original da Lexicografia portuguesa da época, e o Diccionario Comtemporaneo da Lingua Portugueza, de Caldas Aulete, que foi publicado em 1881, sendo o primeiro grande dicionário a ser publicado no século XIX (BIDERMAN, 1984; VERDELHO, 2002; VERDELHO, 2007).

Além de apresentar vocábulos abonados por mestres das letras portuguesas, o Aulete apresenta uma variedade de informações importantes acerca das entradas presentes no dicionário. Assim, “[...] Caldas Aulete esboça uma incipiente reflexão lexicográfica que merece leitura, sobretudo pelo diagnóstico crítico sobre 'o estado em que se acham os estudos da sciencia lexicologica' portuguesa [...]" (VERDELHO, 2007, p. 39). O autor, então, prepara um dicionário voltado aos usos, pois os dicionários portugueses eram voltados para a escolarização. Assim, de acordo com Verdelho (2002, p.42-43), o Diccionario Comtemporaneo da Lingua Portugueza é estruturado em quatro parâmetros lexicográficos:

1) A "formação" das palavras, que inclui a via popular, a via literária (erudita), e ainda os estrangeirismos, os neologismos resultantes do percurso 
histórico da língua, a onomatopeia, e as terminologias da ciência e da técnica. A propósito da "formação", reflecte-se também sobre a analogia e sobre a etimologia.

2) A "orthografia" que se pretende predominantemente "fonética" para as "palavras populares" e "etymologica" para os "termos de origem erudita e historica".

3) A "pronunciação", para a qual se invoca a autoridade de António J. Viale e Gonçalves Viana, e que se baseia no princípio simplista e tradicional, lapidarmente enunciado: "São as pessoas eruditas e illustradas da corte as que dão a lei e estabelecem o typo da mais aprimorada pronunciação das linguas". Parece ter tido escassa repercussão na feitura do dicionário.

4) A "significação" que se limita a uma brevíssima reflexão sobre as variações diacrónicas e estilísticas.

Aulete, ainda, apresenta informações quanto ao uso gramatical e outras informações lexicográficas que são importantes ao verbete. Tais fatos fizeram deste dicionário um importante patrimônio dos estudos linguísticos, pois ele apresenta

[...] uma importante actualização da nomenclatura lexical da língua portuguesa, por um esforço de rigor na utilização e nas referências das abonações, pela informação etimológica e gramatical e por uma cuidadosa classificação das variedades diacrónicas, geográficas e estilísticas [...] (VERDELHO, 2007, p. 40)

demonstrando a importância da obra lexicográfica para os estudos da LP.

Há ainda outras obras da Lexicografia de Língua Portuguesa como o Novo diccionario da língua portuguesa, de Cândico Figueiredo, publicado no final do século XIX, o Dicionário geral e analógico, de Artur Bivar, que foi postumamente publicado, e o Dicionário da língua portuguesa, da Academia das Ciências de Lisboa, a qual, em 1976, iniciou uma nova tentativa de publicação, entre outros, que apresentam certa relevância ao fazer lexicográfico português. Contudo, a exposição feita até aqui cumpre o propósito de fazer uma breve apresentação da Ciência Dicionarística de Portugal e apontar os pontos desse percurso que influenciaram a do Brasil. Assim, passamos agora a olhar um pouco da história dos dicionários elaborados em terras brasileiras.

\section{OS DICIONÁRIOS NO BRASIL}

A história dos dicionários no Brasil pode ser contada por, pelo menos, três pontos de vistas diferentes, que levam em conta diversos momentos da história do Brasil. As listas de palavras, contudo, começaram a ser produzidas ainda no século XVI, pois havia uma necessidade de comunicação dos colonizadores com os habitantes do dito "novo mundo", os índios. Por isso, os viajantes que vinham de Portugal para o 
Brasil produziram listas que intentavam facilitar a comunicação com o povo indígena. Partindo dessa informação, encontramos algumas importantes considerações acerca do ponto de origem da Lexicografia brasileira. Nesse sentido, Nunes (2002) afirma que

\begin{abstract}
se consideramos a unidade da palavra, desde os primeiros relatos de viajantes temos um saber que se volta para os termos empregados no Brasil, sejam as nomeações em língua portuguesa, desde Caminha (1500), sejam termos indígenas traduzidos e comentados, desde Pigafeta, em 1519[...]. Se consideramos a forma acabada do dicionário, os bilíngues português-tupi foram os primeiros a aparecer, na Época Colonial (séc. XVI-XVII). Se consideramos o dicionário monolíngue, o de Moraes (1789) foi o primeiro a ser amplamente utilizado, inaugurando a série de transferências de dicionários portugueses, que seguirá com Aulete (1881), Figueiredo (1899) e outros. Ainda quanto ao monolíngue, se consideramos a produção local, destacam-se na segunda metade do século XIX os dicionários de complemento, como o de Costa Rubim (1853), os de regionalismos, como o de Antônio Coruja (1856) e os de brasileirismos, como os de Macedo Soares (1888) e Beaurepaire Rohan (1889). (NUNES, 2002, p. 101-102)
\end{abstract}

A partir dessas considerações, tomamos, como ponto de partida da Lexicografia brasileira, as listas de palavras que os colonos e viajantes produziram em solo brasileiro. Entendendo, com isso, que esses textos “[...] podem ser considerados precursores de um discurso lexicográfico brasileiro [...]" (NUNES, 2006, p. 60), porque, além da presença do discurso da Lexicografia evidente nelas, é a partir dessas listas que se pode fazer um estudo dos itens lexicais daquela época. Pontuamos, também, que os estudos lexicográficos brasileiros, a exemplo de Portugal, passaram por uma fase de dicionários bilíngues e uma de monolíngues, portugueses publicados no Brasil e aqueles produzidos por brasileiros; essa trajetória desenvolveu-se do século XVII ao XIX. Temos, a partir das listas de palavras e outros textos de teor lexicográfico, a produção de alguns dicionários em terras brasileiras.

Como em Portugal, os jesuítas tiveram um importante papel na história da Lexicografia brasileira, foram eles os responsáveis pela produção de dicionários bilíngues, que abordavam o Português e o Latim. Enquanto em Portugal essas obras lexicográficas tinham a função de escolarizar em língua latina, no Brasil, elas intentavam fazer com que os padres pudessem se comunicar com os indígenas, visando a catequizá-los, por isso eram obras português-tupi. Essa obra foi chamada de Vocabulário da língua brasílica ou da língua da costa, pois assim chamavam a língua falada no litoral do Brasil (BIDERMAN, 1984; NUNES, 2002; NUNES, 2006; FARIAS, 2007). 
Alguns dicionários que foram primeiramente publicados Portugal foram publicados, também, em terras brasileiras. Entre eles, temos as últimas publicações do dicionário de Morais e Silva e algumas edições do dicionário de Caldas Aulete, que se tornaram importantes para história da Lexicografia no Brasil. Além deles, desenvolveram-se dicionários nacionais, que surgiram na segunda metade do século XIX. Frisamos que a chegada da família real portuguesa ao Brasil, em 1808, e a proclamação da independência brasileira, em 1822, foram importantes acontecimentos, marcando tanto a história do país, como os estudos linguísticos e a produção lexicográfica. Outro acontecimento que marca os estudos linguísticos brasileiros é a fundação da Academia Brasileira de Letras (ABL) em 1897.

É, porém, o século XX, que marca a Lexicografia brasileira, visto que este traz muitas inovações em diversos campos de estudos, incluindo o lexicográfico, e novos autores se lançaram à produção de dicionários nacionais. Nesse sentido, Krieger et alli (2006, p.174) afirmam que o século que ora abordamos "representa um marco histórico na lexicografia brasileira. É neste período que surgem os nossos primeiros dicionários, editados seja em coedição com Portugal, seja exclusivamente por editora nacional". Podemos identificar que, nesse período, publicam-se importantes dicionários de Língua Portuguesa no Brasil.

Entre eles, temos um Vocabulário de Brasileirismos da Academia Brasileira de Letras, que fora elaborado por Machado de Assis e que não chegou a ser publicado (NUNES, 2002; BIDERMAN, 2003; KRIEGER et alli, 2006; NUNES, 2006). Após isso, Laudelino Freire apresentou à ABL uma proposta de uma obra que seria o dicionário da Academia. Porém,

como o projeto da ABL se desenvolvia lenta e precariamente, Laudelino
decidiu elaborar um dicionário do português e montou sua equipe para tal
fim. O Grande e novíssimo dicionário da língua portuguesa, organizado por
Laudelino Freire, foi publicado no Rio de Janeiro de 1939 a 1944.
Organizado em cinco volumes, o dicionário (FREIRE, 1939) prima pela
riqueza vocabular, com a inclusão de muitas locuções e expressões,
neologismos e termos técnicos, além de outras qualidades como numerar as
acepções das palavras-entrada. (BIDERMAN, 2003, p. 57, grifo da autora)

O dicionário de Freire tornou-se o primeiro grande dicionário a ser publicado por um brasileiro e a apresentar uma grande recolha de palavras visando a atender a portugueses e brasileiros. Sem levar em conta as divergências entre as duas variedades do português, também buscou apontar neologismos e termos técnicos com as suas 
abonações. Além disso, Laudelino Freire apresenta grande qualidade lexicográfica; dessa forma, mesmo com alguns defeitos, esse dicionário se torna uma importante fonte para os estudos lexicais brasileiros e uma importante referência para diversas pesquisas de cunho lexicográfico (NUNES, 2002; BIDERMAN, 2003; KRIEGER et alli, 2006).

Apesar de sua grande importância, o dicionário de Laudelino Freire ainda não era o dicionário da ABL; por isso, Antenor Nascentes foi incumbido, pela academia, de elaborar o dicionário que deveria seguir como "[...] modelo o Diccionario de Ia Real Academia Espanhola (Drae) [...]" (BIDERMAN, 2003, p. 58, grifo da autora) e que carregaria o título de dicionário da academia. Assim, em 1943, Nascentes entregou à Academia Brasileira de Letras os seus manuscritos, porém o dicionário só foi publicado, em cinco volumes, a partir de 1961, sendo publicado até o ano de 1967. Biderman (2003, p.58) afirma que

a nomenclatura do dicionário de Nascentes (1961), ou da Academia Brasileira de Letras, totaliza aproximadamente 100.000 verbetes. Não há abonações nos verbetes; quando necessário para o entendimento da definição, o dicionarista criou exemplos, que são, porém, raros. Apesar das muitas qualidades desse dicionário, ele também não teve grande fortuna.

Vemos que, apesar das suas qualidades, o dicionário de Nascentes não foi alçado à posição de dicionário nacional, isto é, ele não teve, como pretendia, o status de dicionário da Academia. Tal fato deu-se

primeiro, porque foi publicado muitos anos depois de concluído e não há nada que envelheça mais do que o léxico; segundo, porque resultou em obra volumosa e o público comprovadamente prefere compulsar uma obra lexicográfica em apenas um volume e que lhe custe menos (BIDERMAN, 2003, p. 58).

Assim, o dicionário de Nascentes, apesar de não alcançar o patamar ao qual se propôs, tornou-se uma grande e importante fonte para a Lexicografia brasileira.

Apesar dos esforços com o dicionário de Antenor Nascentes, a ABL ainda está em débito em relação à produção de um dicionário da Academia. Nesse percurso, em 1975, Aurélio Buarque de Holanda Ferreira publicou o seu Novo Dicionário da Língua Portuguesa, o qual, popularmente, ficou conhecido como Dicionário Aurélio. Essa é "a obra que alcança a repercussão que a Academia esperava, e que consagra o léxico do PB” (KRIEGER et alli, 2006, p. 183). O Aurélio ganhou, portanto, grande distinção na Lexicografia brasileira, possuindo cerca de 150 mil verbetes, sendo reeditado em 1986, 
1999 e 2004, chegando a um total de 435 mil entradas (BIDERMAN, 2002; BIDERMAN, 2003; KRIEGER et alli, 2006).

O dicionário Aurélio, segundo Krieger et alli (2006), apresentou, em 25\% de sua obra, brasileirismos que foram coletados em diversas fontes, o que o levou à estatura de importante fonte para os estudos linguísticos, seja por uma vertente lexicográfica, seja por outros vieses, principalmente os que tratam das questões entre a variedade portuguesa e a brasileira. Assim,

mesmo com limitações, a obra de Aurélio determina a feição do léxico vigente no Brasil. Além da grande representatividade, pode-se dizer que, com o Aurélio, as discussões sobre a autenticidade ou a identidade da língua portuguesa falada no Brasil acabam por perder o sentido (KRIEGER et alli, 2006, p. 183).

Esse é um fato que leva o Novo Dicionário da Língua Portuguesa a ser amplamente utilizado em Portugal (BIDERMAN, 2002; BIDERMAN, 2003; KRIEGER et alli, 2006).

Depois do dicionário Aurélio, a grande obra da lexicografia brasileira foi o Dicionário Houaiss da Língua Portuguesa, também conhecido como Dicionário Houaiss, o qual "foi idealizado pelo filólogo Antônio Houaiss e resulta de anos de estudos e anotações, refletindo toda sua erudição e visão arguta de nossa língua" (BARBOSA, 2013, p. 1). Houaiss apresentou um grande projeto para o desenvolvimento de um importante e amplo dicionário de língua, o qual foi editado com o auxílio do lexicógrafo Mauro de Salles Villar. O Dicionário Houaiss foi publicado, pela primeira vez, no ano de 2001 e sua edição mais recente data do ano de 2009.

O Houaiss tornou-se uma obra muito importante e de grande distinção para os estudos lexicográficos, não só à Lexicografia brasileira, mas para a de língua portuguesa de uma maneira geral. Essa distinção, segundo Barbosa (2013, p.1), se dá por duas principais razões:

1) o esforço para alcançar o âmbito lusofônico de descrição, com contratação de profissionais de diferentes países de língua portuguesa para realizar pesquisas abrangentes a respeito da diversidade do vocabulário da língua portuguesa; 2) a perspectiva filológica, com consistente embasamento histórico na estruturação dos verbetes.

Esse dicionário tornou-se, então, uma consistente fonte de referência lexicográfica para a os estudos lexicais em Língua Portuguesa. Isso se dá porque o Houaiss apresenta um grande repertório de itens léxicos que compõem as diversas 
variedades do português. Tal fato se fez possível porque havia "uma numerosa equipe de redatores que trabalhou de modo entrosado principalmente no Brasil e em Portugal, mas também em Angola, Cabo Verde, Guiné-Bissau, Macau, Moçambique e São Tomé e Príncipe" (BARBOSA, 2013, p. 1), o que foi de fundamental importância para os estudos lexicográficos da LP, principalmente no tocante às questões de variação linguística.

Com isso, vemos que o percurso da Lexicografia brasileira passou por muitos momentos até se estabelecer; ela começa com listas de palavras e caminha até chegar ao trabalho de Antônio Houaiss com o Dicionário Houaiss da Língua Portuguesa. É assim que o Brasil ganha espaço nos estudos lexicográficos de Língua Portuguesa, mas ainda há muito que se estudar, tanto no campo da Lexicografia, quanto no da Lexicologia. Assim, passamos a um estudo acerca do vocábulo profeta.

\section{PROFETA: PERCURSO HISTÓRICO}

A palavra profeta é muito comum no dia a dia da sociedade brasileira, principalmente em se tratando do discurso religioso, visto que este está, a cada dia, tomando mais espaço em nossa sociedade e abrangendo diferentes ambientes comunicativos. Assim, buscamos traçar uma linha histórica das significações desse termo na Lexicografia de LP. Para esse fim, analisamos a entrada para este vocábulo em quatro diferentes dicionários do português: o Bluteau, o Caldas Aulete, o Nascentes e o Houaiss. Buscamos selecionar os dicionários pelo destaque que apresentaram em seu tempo e ainda apresentam em relação aos estudos diacrônicos da língua; o Nascentes foi escolhido, em lugar do Aurélio, por ter pretendido o status de Dicionário da ABL.

Assim, a partir dessas obras, que foram publicadas em épocas diferentes e que representam importantes contribuições ao campo lexicográfico, traçamos algumas comparações entre as definições presentes neles com vistas a produzir uma pequena linha histórica para tal palavra, no português. Assim, começaremos pelo Bluteau, que apresenta a seguinte definição para a palavra em questão: 
Figura 1: Página do Vocabulário de Bluteau.

778

PRO

cafiáo. Propenfus ad bene merendum. Cic: Propento aos goftos, \& paffatem pos da vida. Ad voluptatem propenfior. Cic. (He Propen $/ a, \&$ applicada a remediar, $\&$ fuprir todas as faltas. Vieyra, tom. 6. pag. 364.)

Prophec1a, ou Profecia. Predicção de Propheta. A verdadeyra profecia he huma intelligencia, \& conhecimento fo. brenatural de coufas diftantes, ou futuras, por infpiraçăo Divına ; fegundo S. Paulo na Epift. 20 Corinthios, cap. I 2. he hum dos Dons do Efpirito Santo.Pro. phetia, e. Fem. He o termo da Igreja.Va. ticinatio, onis. Fem. Cic. I'aticinium, ii. Neut. achey efta ultima palavra nocap. 52. do livro 7. de Plinio Hift. aonde diz, Plena prateren vita eft his vaticiniis.

Livros de Prophecias. Libri vatici. ni, orum. Plur. Mafc. Tit. Liv.

Prophet a, ou Proteta. Derivafe das duas palavras Gregas Pro, que val o mefmo que Ante, ou dantes, \& Phimi, quer dizer Digo, de forte que Prophera vem a fer o mefmo, que aquelle q̃ diz as coufas antes que aconteção; outros derivão Propheta do Grego Phatos, donde os Latinos derivaraó Fatus, \& fateor. Nefta fua mais ampla fignificação, efta palavia Propheta fe póde attribuir a qualquer que por impulfo natural,ou com efpirito profetico diz algũa coufa primeyro que fucceda. E nefte fentido foy Platâo Propheta; porque no livro 4, de Legibus diz, que $E$ im todas as coufas Deos havin de fer a regra certa das operaçoens dos bomens, particularmente $f e \mathrm{em}$ alg $\breve{a}$ p parte do mundo honver a, ou devia haver hum Deos ho. mem. Os Egypcios chamárāo Prophetas os q́ elcreverāo a Hiftoria das fuas na. çóes, \& nefte fentido fe ha de entendero que Clemente Alexandrino efcreveo no primeyro livro das fuas $T$ a peçarias, a faber, que Thales, \& Pithagoras tıverāo varias conferencias com os Prophetas dos Egypcios: nifto fe conformáraó os Egypcios comlos Hebreos, que tambem chamárāo a alguns ftus Hiftoriadores Prophetas; \& no feu primeyro livro contra'A pion, o confirma Jofepho, dizen:

\section{PRO}

do que os que efcrevéraó os Annaes da fua nação, foráo chamados Prophetas, \& provas difto fe acháo no livro dos $\mathbf{P a}$ : ralipomenos, nos quaes fe falla de $\mathrm{Na}$ than, Gad, Abias, \& alguns outros que efcrevérão as Hiftorias daquelle tempo. He ifto tanto affim, que a palavra Navi, que na verfaó da fagrada Efcritura os Setenta Interpretes traduzirāo nefta de Propheta, legundoalgús Doutores Hebreos, \& particularmente, fegundo Sala. mão $\mathbf{f a r c h t}$, fe deriva do Hebraico Nou, que val o mefmo que Fallar, como fe entre os Hebreos, os Prophetas houveffem fido os Oradores, que declaraváo ao po. vo a vontade de Deos, com as praticas que fazião, ou com os livros que efcre. vıáo. E por efla razão os Judeos dividem os livros propheticos em duas clafles, a primeyra contém os a que elles chamăo Neviim rifconim, que val o mefmo que Prophetas primeyros, \& neftes fe com pre: hendem os livros de Jofué, dos Juizes, os dous livros de Samuel, \& os quatro livros dos Reys : da legunda claffe faó, Ifaias, Jeremias, \& os mais Prophetas, a q elles cham ao Neviim aharonim, id eft, Prophetas pofteriores. Proccpio, Theodoreto, \& outros Padres Gregos fe conformão nefte particular com os Judeos; porque affirmăo que os Prophetas efcre: vérăo as Hiftorias do feu tempo, de maneyra porèn, que ainda que Hiftoriado. res não deyxăo de dizer muytas profe. cias, como fe vé nos livros de Daniel, \& outros. Prophetas tambem forāo chamados huns Sacerdotes, facrifica Jores inimigos do povo Hebreo, como os que Saul, mandado por Samuel, achou em huma Cidade dos Philifteos. Varios $\mathrm{fa}_{\mathrm{a}}$ cerdotes idolatras, \& impoftores enganárăo ao povo dizendo, que vinhāo da parte de Deos annunciarlhe os futuros. Os quatrocentos \& cincoenta Prophetas de Baal, \& outros quatrocentos Prophe. tas dos matos, a que Jefabel mantinha (como fe ré no 3. livro dos Reys, cap. 18) erão todos hús famolos embuftey. ros. Defta mefma clafle faó os prophc. tas dos Gentios, na India, \& em outras 
Figura 2: Página do Vocabulário de Bluteau.

\section{PRO}

terras de infieis, \& na Turquia o celebre impoftor Mafoma. Os fuprefticiofos daó ao Abbade Joachim o titulo de Propheta, com o mefino nome honrāo alguns Francezes ao feu Noltradamo, \& algús Portuguezes ao feu Bandarra. Os verda* deyros Prophetas faó os que infpirados de Deos annunciaó aos homens as fuas Jeys, preceytos, myfterios, \& fucceffos futuros, como Moyfés, David, os quatro Prophetas mayores, \& os doze menores, na fagrada Efcritura, $f$ e bem nem Moyfés, nem David faó numerados en. tre os Prophetas; porque nem hum, nem outro viviaó com o rigor dos antigos Prophetas. Moyfés, conductor do povo de I'́rael , vivia, \& veftia com grandeza; David, como Rey, lograva as delicias, \&: efplendor da Corte. $O$ habito dos ver. dadeyros Prophetas foy ou facco, ou cilicio, para moftrarem que faziáo peni. tencia pelos peccados do povo. Por iffo quádo fe faz mençaó do Propheta Elias fe diz, que era hum homem veftido de pelos, com cingidouro de couro.4. Reg. 1. 8. Quando manda Deos a Ifaias que fe difpa, dizlhe que tire de fi o feu fac. co. Ef̂tes, \& outros Santos Varóes faó os que depois dos Patriarcas obferváraó a tradiçáo mais pura da verdadeyra Religiáo. Occupaváo-fe em meditar na Ley de Deos, fazer oraçáo muytas vezes no dia, inftruir feus difcipulos, explicarlhes os pontos da Ley mais difficultofos , \& as allegorías que refpeytavão o eftado da Igreja depois da vinda do Meffiass \& finalmente em condenar as acçóes peccaminofas , \& exhortar os peccadores a fa. zer penitencia. Efta liberdade em dizer até aos Principes as verdades, os fazia odiolos, \& a muytos lhes cuitou a vida. No mefmo tempo nāo faltárá́ impoltores, q́ arremedando o exterior dos ver: dadeyros Prophetas, tambem andavāo cubertos com faccos. Zachar.13.4.\& dacubertos entender que eráo infpirados de Deos, mas andavão muy attentos em não Deos,mas ao povo, nem pronófticar def. graças aos Principes. Os bons Prophetas graças aos Principecar : a viuva, à qual
PRO 778

multiplicou Elias o azeyte, era viuva de hum Propheta. Finalmente tambem os falfos deofes tiveraó feus prophetas, mas falfos, como o forāo os oitocentos \& cincoenta a que Elias fez jult içar. 3. Reg.r 8. 19. Semelhantes a eftes erāo na Grecia os adevinhos, a que os Gregos chamavăo Manteis, como nos tempos Heroicos, Calcas, \& Tirefias. Até os que pronunciavão, \& publicavão os Oraculos paf. favão por Prophetas, \& juntamente erāo tidos por Prophetas os Poetas, que fe jactavão ferem infpirados de Deos; por:que nāo fe faziāo ter nefta conta, por fal: larem poeticamente; mas porque na rea. lidade, quer por obra do demonio, quer por artificio, entravāo em furor, \& nelles fe viăo os effeytos fenfiveis, que o Efpirito Divino caufava nos verdadeyros Prophetas. Propheta, a. Mafc. Vates, is. Mafc. A palavra Propheta nefte fentido he meramente Ecclefiaftica; em outro fentido ufárāo della os Authores Gen. tios. Veja o curiolo a Voffio, no feu livro das Etymologias da lingua Latina fobre a pálavra Propheta. Fallando nos Santos Prophetas, eu acrefcentára a Vates algú epitheto, como Sanctus, ou Jacer, ou di, vino firitu afflatus vates, $\& c$.

Prophetar. Em Joáo de Barros, \& outros Autores fe acha por Propherizar.

Propheticamente. Prophetizando, fallando como Propheta, \&c. Va. tem in morem, ou vatucinando.

Prophêtrco. A palavra Ecclefiaftica da qual (a meu ver, nos havemos de valer) fallando em coufas fagradas, he Propheticus. Predifle muytas coufas com ef pirito prophetico. DivinoJpiritu afflac tus,multa predixit. Divino afflatus nu: mine, multa vaticinatus $e f t$, ou multa vas ticinia protulit, ou edidit.

Prophetíza. Mulher que prophe:tiza. Em varios lugares da fagrada Efcritura achamos varias Prophetizas, no cap. 15. do Exodo fe falla de Maria Pro. phetiza, irmáa de Moylés; no livro dos Juizes, de Debor2, no livro 4 des Reys。 de Holda; \& nocap. 2. de S. Lucas, de Anna, filha de Phanuel. As Sybillas tiverać

Fonte: BLUTEAU, 1728, p. 779.

Observamos que o Bluteau apresenta informações históricas e morfológicas sobre o vocábulo, apontando os elementos usados na formação do termo. Outra coisa que notamos é a presença de acepções diferentes para a palavra; assim, percebemos noções diferentes para o termo em análise. Essas concepções variam entre os povos e 
seus momentos históricos. O profeta é, então, aquele que fala algo que ainda está para acontecer, ou seja, coisas relacionadas ao futuro e esse seria o significado mais comum da palavra.

Para alguns povos, porém, segundo Bluteau (1728), a ideia de profeta era ligada aos seus estudiosos, aqueles dados à Filosofia, às letras e aos mais diversos estudos. Assim, Platão foi considerado, pelos gregos, como um profeta. Esse povo também atribuía a ideia do profeta aos leitores de oráculos, estes muito ligados aos sacerdotes e sacerdotisas de Delfos; para os egípcios, essa ideia era atribuída aos seus historiadores, retomando a ideia de profetas como estudiosos, pois eles escreviam a história da sua nação. Outros povos são citados pelo dicionarista, porém ele dá maior atenção à concepção estruturada pelo povo hebreu acerca do termo.

Para os hebreus, portanto, o termo possuía duas acepções; uma que também relacionava o sentido do vocábulo aos seus historiadores e estudiosos, talvez por influência do período em que o povo judeu foi escravo no Egito. A segunda, e mais comum entre esse povo, é a ideia de o profeta ser aquele que transmite alguma mensagem sobre o futuro, mas esse era inspirados por Deus, dotando tal previsão de um teor sobrenatural. Para esse povo, dessa forma, o profeta era uma espécie de boca de seu Deus na terra, ou seja, tudo quanto os profetas falavam era tomado como uma mensagem divina, fazendo com que o número de profetas dentre o povo hebreu fosse reduzido a pessoas específicas.

Por fim, observamos que Rafael Bluteau produz um longo texto para o verbete profeta; isso acontece porque o Vocabulário do autor tem um teor enciclopédico, por esse motivo, fora a definição da palavra, há informações históricas que vão para além das questões linguísticas, porém contribuem para a construção do sentido e das acepções do vocábulo. Outro ponto a ser destacado é o fato de Bluteau dar maior evidência ao contexto religioso que é ligado ao cristianismo; provavelmente, isso ocorre pelo fato de o autor ser um padre, tendo, pois, uma ampla formação cristã; corroborando essa formação do dicionarista há a forte presença do cristianismo, por meio da igreja católica, na sociedade portuguesa. Prosseguindo com o trabalho, passamos ao século XIX com o dicionário de Caldas Aulete (1881), que apresenta a seguinte definição:

Propheta (pru-fé-ta), s. $m$. homem que prediz o futuro; vidente. || Titulo dado a Mahomet pelos musulmanos. \| Adivinho, bruxo. \| Nome dado a alguns heresiarchas pelos seus sectários, Hílomem que por conjectura ou por acaso annuncia o que deve acontecer. \(Bibl.) Ü propheta rei ou o rei propheta, 
David, antigo rei do povo judeu. || F. lat. Propheta. (AULETE, 1881, p. 1420, grifos do autor)

Com a passagem do século, vemos que a ideia do termo profeta passa por algumas modificações e, mesmo que não sejam muitas, apresentam determinada relevância à significação do termo. Apesar de continuar a ser atribuído ao campo religioso, o vocábulo ganha acepções que fogem ao campo do cristianismo. Assim, temos a manutenção da concepção de que o profeta é aquele que fala de coisas do futuro, porém, temos no Aulete a atribuição do termo à religião muçulmana, por meio de Mahomet, a quem se atribuía a ideia de profeta. Para além disso, temos essa concepção sendo associada ao vidente, por se tratar de alguém com a capacidade de falar de coisas futuras.

Temos também a concepção de que o profeta é um bruxo, um adivinho, retirando, assim, o termo da ideia de uma pessoa que transmitia uma mensagem mandada pelos deuses, segundo os gregos, e por Deus, segundo os hebreus; para estes tal acepção leva o termo a uma concepção pagã, enquanto que, para aqueles, é apenas mais uma forma de ver sua crença. Percebemos, contudo, que em todas as acepções há a manutenção do caráter sobrenatural que a significação da entrada carrega. Mesmo com todo o distanciamento, a visão do cristianismo continua presente na definição do vocábulo, essa manutenção pode ser atribuída à manutenção da forte presença da igreja católica na sociedade portuguesa, pois, como vimos, muitos dicionários foram elaborados por padres, como os Jesuítas. Em seguida, passamos ao século XX e a um dicionário brasileiro para observarmos a definição dada por Nascentes (1955):

Figura 3: Recorte da página do Dicionário de Antenor Nascentes. PROFESSAP - Do lat. "professare, frequientativo de profiteor, declarar diante de alguém. Especializou o sentido. PROFESSOR - Do lat. professore, o quo declara seus conhecimentos diante de outrem. PROFESTO - Do lat. profestu. PROFETA - Do gr. prophétes, o que prediz (o futuro), pelo lat. propheta. Fonte: NASCENTES, 1955, p. 417.

Observamos, no Dicionário Etimológico de Nascentes, que o vocábulo profeta continua a carregar a noção de ser aquele que transmite uma mensagem acerca do futuro; contudo, não há uma explicitação de alguma filiação religiosa do termo, esta fica 
a cargo das intenções e das práticas comunicativas dos usuários. Observamos que também houve uma redução nas acepções deste verbete, ou seja, dentre as que observamos nos dicionários anteriores só uma definição foi mantida com a passagem do século e com a passagem para a sociedade brasileira.

Apesar de não haver, no Nascentes, uma informação que faça referência ao contexto religioso, o vocábulo é, ainda, usado no ambiente linguístico das diversas religiões existentes; contudo, não há uma clara delimitação da corrente religiosa em que ele é utilizado e como cada religião o utiliza. O dicionarista apresenta, então, um novo tratamento para o vocábulo que estudamos; isso acontece porque ele aponta informações que fazem referência às origens, grega e latina da entrada, sem tecer maiores comentários acerca desse conteúdo histórico sobre a palavra ou ampliar as acepções para o vocábulo. Por último, passamos ao século XXI e analisamos a definição que Antônio Houaiss dá ao verbete:

profeta s.m. (sXIII) 1. REL pessoa que anuncia os desígnios divinos, que prediz acontecimentos por inspiração de Deus <Deus falava aos hebreus através dos seus p.> 2. pessoa que, supostamente, prediz o futuro; vidente, adivinho <na Antiguidade, muitos exerciam o ofício de p.> 3. indivíduo que prevê acontecimentos futuros por dedução ou intuição <ele foi o p. da crise> 4. REL título dado pelos muçulmanos a Maomé, fundador do islamismo inicial maiúsc. 5. ENT m.q. LOUVA-A-DEUS ('designação comum') $\odot$ ETIM lat. prophèta ou prophètes, ae 'sacerdote de um templo, de uma divindade' $\odot$ SIN/VAR ver sinonímia de haríolo $\odot$ HOM profeta (fl. Profetar) (HOUAISS; VILLAR, 2009, p. 1557)

Vemos que, no dicionário Houaiss, pela primeira vez, entre os dicionários que trabalhamos, aparece a datação da palavra, ou seja, é nessa obra que aparece uma data que marca o primeiro registro do uso desse vocábulo em Língua Portuguesa; este é atribuído a algum período do século XIII, não determinando maiores detalhes. Tal prática se faz importante, porque a partir das datações podemos ter uma melhor visão dos desdobramentos históricos da palavra em nosso idioma e entender os motivos que produziram as primeiras concepções dessa entrada nos dicionários e aquelas que levaram a mudanças de acepções, mesmo que, no caso do vocábulo em estudo, tenhamos observado alterações muito significativas nas informações lexicográficas do termo.

Quanto às acepções presentes no Houaiss, observamos que a religiosa, relacionada ao cristianismo, volta às páginas da obra e vem acompanhada, por um exemplo de seu uso em frase, o que é uma novidade entre os dicionários analisados e 
que será usada em outras acepções da mesma entrada. A definição ligada à religião cristã passa ser a primeira a descrever o termo. Em seguida, os dicionaristas apresentam a relação do verbete profeta com as ideias de vidente e de adivinho, como uma pessoa que prediz o futuro e essa ideia de previsão do futuro é ligada a uma dedução ou a uma intuição, dando a entender que estes estão desconectados daqueles que transmitem uma mensagem de Deus; contudo, mostram, ainda, um resquício da ideia do profeta como um transmissor de uma mensagem sobrenatural.

Ao apresentar a quarta acepção, os dicionaristas voltam ao contexto religioso, porém agora apresentam a visão da religião islâmica, que atribui o vocábulo ao seu grande líder, Maomé. Por fim, temos nesse dicionário uma acepção que ainda não tínhamos encontrado nas outras obras que analisamos; essa atribui o termo a um inseto, ligando-o ao campo da entomologia. Compreendemos, então, que a virada do século amplia as significações e os usos do termo estudado.

O Houaiss, à semelhança dos outros dicionários que selecionamos para este trabalho, apresenta um étimo para o vocábulo em estudo, ou seja, uma palavra que originou a que hoje conhecemos e à qual atribuímos as acepções aqui discutidas. Nos quatro dicionários que analisamos, aponta-se como étimo o latim. Porém, vemos que o Bluteau, o Aulete e o Nascentes apresentam também o grego como língua de origem para o termo. Além disso, o Bluteau, por ter características enciclopédicas, aponta informações acerca de outros idiomas e, por isso, fala do percurso do vocábulo em outras línguas, mas não as aponta como étimos possíveis para o termo que conhecemos hoje.

\section{PALAVRAS FINAIS}

Observamos, durante o desenvolvimento do trabalho, que poucas mudanças ocorreram com a definição do vocábulo profeta. Assim, percebemos que há uma acepção que se repete nos quatro dicionários que analisamos: a definição que trata profeta como aquele que transmite uma informação ou mensagem sobre o porvir, isto é, acerca do futuro. Em três dos dicionários, Bluteau, Aulete e Houaiss, apresenta-se uma acepção que trata do contexto religioso cristão. O Aulete e o Houaiss informam definições que são ligadas a outros contextos religiosos, tratando da religião islâmica, 
da religião muçulmana e das religiões e da cultura grega; tais acepções, ao apontarem um ser divino como origem das mensagens acerca do futuro, dão ao vocábulo um caráter sobrenatural, por exemplo, a visão do profeta como "boca de Deus". Encontramos também, no Houaiss, uma acepção que coloca o vocábulo no campo da entomologia, ciência que estuda os insetos.

Outro ponto que podemos comentar é a presença de informações etimológicas acerca do vocábulo, apresentando importante informação para a história da palavra e também para os estudos linguísticos e lexicográficos. Informação que também se faz muito valorosa para os estudos diacrônicos da língua é a datação do registro mais antigo do termo dentro da cultura de Língua Portuguesa, neste caso o vocábulo profeta. Tal fato permite que lexicógrafos e outros linguistas possam construir estudos mais profundos acerca das palavras que compõem o léxico de uma língua. Essa informação, no presente trabalho, só foi encontrada no dicionário Houaiss.

Apesar de não encontrarmos uma grande diferença entre as acepções dos diferentes dicionários para o verbete profeta, percebemos que houve uma mudança na forma como as definições para este termo eram construídas. Vemos, com isso, um texto amplamente histórico e enciclopédico no Bluteau; um mais contido e preso às questões linguísticas no Aulete. Em contrapartida vemos, no Nascentes, um texto muito reduzido, apresentando apenas uma acepção e informações etimológicas e, por fim, o Houaiss amplia as definições apontando datação, cinco acepções, informações etimológicas e exemplos para os usos da palavra estudada.

Percebemos, por fim, que ainda há um longo caminho para as ciências lexicográficas de Língua Portuguesa, no nosso caso, focando a Lexicografia e a Lexicologia brasileiras. Isso se dá porque há muitos estudos que precisam ser feitos no tocante ao léxico do português brasileiro e também das outras variedades, principalmente em textos dos séculos XIX e XX. Faz-se preciso, portanto, que haja maiores estudos lexicográficos dos nossos autores, dos arcaísmos da língua, das palavras de origem Tupi e das de origens africanas. Outro ponto importante é, também, a produção de um dicionário da Academia Brasileira de Letras, para assim termos uma Lexicografia ainda mais consistente. 


\section{Referências}

AULETE, Caldas. Dicionario contemporaneo da lingua portugueza. vol. 2. Lisboa: Imprensa Nacional, 1881.

BARBOSA, Flávio de Aguiar. A crítica textual e sua relevância para trabalhos lexicográficos de perspectiva histórica. In: Anais do IV Simpósio Mundial de Estudos de Língua Portuguesa, 2013. Disponível em: http://www.josepereira.com.br//simelp_anais_simposio11(11).pdf. Acesso em: 26 jul. 2018.

BIDERMAN, Maria Tereza Camargo. A ciência da lexicografia. Alfa, São Paulo, v. 28(supl.), p. 1-26, 1984. Disponível em: https://periodicos.fclar.unesp.br/alfa/issue/view/284/showToc. Acesso em: 26 jul. 2018.

BIDERMAN, Maria Tereza Camargo. Análise de dois dicionários gerais do Português Brasileiro contemporâneo: o Aurélio e o Houaiss. Filologia e Linguística Portuguesa, n. 5, p. 85-116. 2002. Disponível em: https://www.revistas.usp.br/flp/issue/view/4911. Acesso em: 26 jul. 2018.

BIDERMAN, Maria Tereza Camargo. Dicionários do português: da tradição à contemporaneidade. Alfa, São Paulo, v. 47, n. 1. p. 53-69. 2003. Disponível em: https://periodicos.fclar.unesp.br/alfa/issue/view/304/showToc. Acesso em: 26 jul. 2018.

BLUTEAU, Raphael. Vocabulario portuguez e latino, aulico, anatomico, architectonico... Coimbra: Collegio das Artes da Companhia de Jesus, 1712-1728. 8 v..

CARDIM, Fernão [Padre]. Tratados da terra e da gente do Brasil. Introducções

CAMERON, Helena Freire. Prosodia e Thesouro da lingoa portuguesza de Bento Pereira. In: VERDELHO, Telmo; SILVESTRE, João Paulo (Orgs.). Dicionarística portuguesa: inventariação e estudo do património lexicográfico. Aveiro: Universidade de Aveiro, 2007.

CUNHA, Antônio Geraldo da. O vocabulário português: perspectivas para a realização de estudos lexicológicos e de trabalhos lexicográficos nos países de língua portuguesa. In: PEREIRA, Maria Teresa G. (Org.). Língua e linguagem em questão. Rio de Janeiro: EdUERJ, 1997. p. 319-330.

FARIAS, Emilia Maria Peixoto. Uma breve história do fazer lexicográfico. Revista Trama, v. 3, n. 5, $1^{\circ}$ Semestre de 2007. p. 89-97. Disponível em:

http://saber.unioeste.br/index.php/trama/issue/view/141/showToc. Acesso em: 26 jul. de 2018.

HOUAISS, Antônio; VILLAR, Mauro de Salles. Dicionário Houaiss da Língua Portuguesa. Rio de Janeiro: Objetiva, 2009. 
KRIEGER, Maria da Graça; MÜLLER, Alexandra Feldekircher; GARCIA, Andréa Roberta da Rocha; BATISTA, Rosinalda Pereira. O século xx, cenário dos dicionários fundadores da lexicografia brasileira: relações com a identidade do português do brasil. Alfa, São Paulo, v. 50, n. 2., p. 173-187, 2006. Disponível em: https://periodicos.fclar.unesp.br/alfa/issue/view/311/showToc. Acesso em: 26 jul. de 2018.

NASCENTES, Antenor. Dicionário etimológico da língua portuguêsa. Rio de Janeiro: Academia Brasileira de Letras, 1955. Tomo 1.

NUNES, José Horta. Dicionarização no Brasil: condições e processos. In: NUNES, José Horta; PETTER, Margarida. História do saber lexical e constituição de um léxico brasileiro. São Paulo: Humanitas/FFLCH/ USP: Pontes, 2002.

NUNES, José Horta. Dicionários no Brasil: análise e história. Campinas, SP: Pontes Editores - São Paulo, SP: Fapesp - São José do Rio Preto, Sp: Faperp, 2006.

SILVESTRE, João Pedro. Vocabulario portuguez, e latino de Rafael Bluteau. In:

VERDELHO, Telmo; SILVESTRE, João Paulo (Orgs.). Dicionarística portuguesa: inventariação e estudo do património lexicográfico. Aveiro: Universidade de Aveiro, 2007.

VERDELHO, Telmo; SILVESTRE, João Paulo (Orgs.). Bluteau e as origens da lexicografia moderna. Lisboa: Imprensa Nacional-Casa da Moeda, 2008. Disponível em: http://www.clul.ulisboa.pt/files/joao_silvestre/silvestre_2008_bluteau_origens.pdf. Acesso em: 26 jul. 2018.

VERDELHO, Telmo. Dicionários portugueses: breve história. In: NUNES, José Horta;

PETTER, Margarida. História do saber lexical e constituição de um léxico brasileiro. São Paulo: Humanitas/FFLCH/ USP: Pontes, 2002.

PETTER, Margarida. Dicionários portugueses, breve história. In: VERDELHO, Telmo; SILVESTRE, João Paulo (Orgs.). Dicionarística portuguesa: inventariação e estudo do património lexicográfico. Aveiro: Universidade de Aveiro, 2007.

PETTER, Margarida. Dicionário de Jerónimo Cardoso. In: VERDELHO, Telmo; SILVESTRE, João Paulo (Orgs.). Dicionarística portuguesa: inventariação e estudo do património lexicográfico. Aveiro: Universidade de Aveiro, 2007.

Recebido em: 17/05/2020

Aceito em: 01/08/2020 